\title{
Reflexões Sobre a Educação Ambiental no Distrito Federal
}

\author{
Marília Luiza Peluso \\ Roberto Sousa
}

p. $50-72$

Como citar este ar tigo:

PELUSO, M. L., Roberto Sousa. REFLEXÕES SOBRE A EDUCAÇÃO

AMBIENTAL NO DISTRITO FEDERAL

Revista Eletrônica: Tempo - Técnica - Território, v.1, n.3 (2010),

p. 50:72 ISSN: 2177-4366.

DOI: https://doi.org/10.26512/ciga.v1i3.15789

Disponível em: http://inseer.ibict.br/ciga/index.php/

ciga/article/viewFile/288/207

Este obra está licenciado com uma Licença Crea tive Commons Atribuição-NãoComer cial 4.0 Inter nacional.

Tempo - Técnica - Território,

V.1, N.1 (2010), 50:72

ISSN: 2177-4366

DOI: https://

doi.org/10.26512/

ciga.v1i3.15789 


\title{
REFLEXÕES SOBRE A EDUCAÇÃO AMBIENTAL NO DISTRITO FEDERAL
}

\author{
Roberto Sousa \\ Bacharel e Licenciado em Geografia pela Universidade de Brasília (2006), especialista em \\ Geoprocessamento pelo Centro Universitário UNIEURO de Brasília (2008), mestrando do \\ Departamento de Geografia da Universidade de Brasília, com concentração em Gestão Ambiental. \\ Atualmente trabalha como Técnico de Sistemas de Saneamento na Companhia de Saneamento \\ Ambiental do Distrito Federal (CAESB). \\ Correspondência: Q. 201 Conj. 04 Casa 16. Recanto das Emas - DF. CEP: 72.610-104. \\ E-mail: roberto.sb@ibest.com.br
}

\section{Marília Luiza Peluso}

Possui graduação em Geografia pela Universidade Federal de Santa Catarina (1962), especialização em Arquitetura e Urbanismo pela Universidade de Brasília (1978), mestrado em

Arquitetura e Urbanismo pela Universidade de Brasília (1983) e doutorado em Psicologia (Psicologia Social) pela Pontifícia Universidade Católica de São Paulo (1998). Atualmente é Professor adjunto da Universidade de Brasília. Tem experiência na área de Geografia, com ênfase em Geografia Humana. Atuando principalmente nos seguintes temas: habitação, representações sociais, espaço.

Correspondência: Universidade de Brasília - UnB, Instituto de Ciências Humanas - IH, Departamento de Geografia. Caixa Postal: 4661. CEP: 70.919-970.

E-mail:peluso@unb.br 
RESUMO: A presente pesquisa procurou verificar se a educação ambiental oferecida pelo governo no âmbito do distrito federal conduz à participação do cidadão comum na busca de soluções para os problemas ambientais observados nesta unidade da federação. para que o objetivo da pesquisa fosse alcançado foi aplicado um questionário a cidadãos do distrito federal e entorno, além da realização de duas entrevistas com especialistas em educação ambiental com atuação no distrito federal. os resultados sugerem que as iniciativas de educação ambiental desenvolvidas pelo governo no distrito federal ainda não foram capazes de modificar os hábitos do cidadão, que contribui de forma insatisfatória para a melhoria da qualidade do ambiente.

PALAVRAS-CHAVE: Educação Ambiental - Governo - Problemas Ambientais- Natureza

\begin{abstract}
The present study investigated if the Environmental Education offered by the government under the Federal District leads the participation of ordinary citizens in finding solutions to environmental problems observed in this unit of the federation. For the research objective was reached a questionnaire was given to citizens of the Federal District and environs, in addition to conducting two interviews with experts on environmental education activities with the Federal District. The results suggest that the Environmental Education initiatives developed by government in the Federal District have not yet been able to change the habits of citizens, which contributes to improving the poor quality of the environment.
\end{abstract}

KEY WORDS: Environmental Education - Government - Environmental Problems - Nature

\title{
INTRODUÇÃO
}

As revoluções econômicas e culturais ocasionadas pela ascensão do sistema capitalista produziram uma sociedade fundamentada no conhecimento científico para a dominação da natureza e para o aumento constante da produção e do consumo. A lógica do capitalismo tornou-se mundializada e, assim, a ciência, a técnica, o consumismo, a visão da natureza como fornecedora de matéria prima permitiram que o ser humano interferisse no ambiente de forma crescente. "É óbvio que este sistema é não-sustentável" (DIAS, 2004, p.11). A ciência moderna, por sua vez, mostrou que os recursos naturais são finitos, que a destruição do meio ambiente pode significar estagnação econômica e que o desequilíbrio nos ecossistemas também ameaça a existência humana. 
Conferências internacionais, leis, programas de gestão são realizados com o intuito de amenizar os impactos produzidos no ambiente, reduzir a possibilidade de estagnação econômica e manter uma boa qualidade de vida "para as presentes e futuras gerações" (BRASIL, 1988, art. 225). O sucesso dessas ações depende da participação de cada um nas medidas de preservação e conservação ambientais. Desta forma, a educação ambiental (EA) apresenta-se como uma ferramenta indispensável para a sensibilização e direcionamento da conduta humana para a preservação do meio ambiente.

Percebendo a importância da EA e seguindo uma tendência mundial, o Distrito Federal (DF) implementou sua Política de Educação Ambiental através da lei distrital número 3.833, de 27 de março de 2006, bem como desenvolveu diversas ações de cunho preservacionista e educativo. Mas, apesar dos esforços, os problemas ambientais permanecem e boa parte com a conivência do próprio cidadão, supostamente informado sobre as questões que envolvem as relações sociedade/natureza. Isto leva a questionar se as ações de EA desenvolvidas no DF são suficientes para alcançar as pessoas de forma satisfatória e produzir melhor qualidade ambiental.

O objetivo do presente trabalho é desenvolver uma reflexão sobre a eficácia da EA oferecida pelo governo do DF para o desenvolvimento da participação do cidadão na resolução dos problemas ambientais.

Uma análise preliminar da questão leva a supor que a EA oferecida no DF não foi capaz de orientar o comportamento dos seus moradores para práticas compatíveis com a manutenção da qualidade ambiental.

A reflexão sobre a EA no DF é necessária para que se busque seu aperfeiçoamento, a fim de que ela possa contribuir melhor com a conscientização da sociedade, para a melhoria da qualidade de vida da população do Distrito Federal e para a promoção da proteção da natureza sem prejudicar o desenvolvimento social e econômico. Este trabalho se concentra nas iniciativas de EA desenvolvidas pelo governo do DF, pois é reconhecido "o dever estatal de protagonizar as ações necessárias ao estabelecimento de uma Política Distrital de Educação Ambiental” (MAIOR e MAURY, 2009, p.03), embora se admita a importância de iniciativas da sociedade civil organizada, das empresas e da sociedade como um todo.

Para que o objetivo do trabalho fosse alcançado, realizou-se uma pesquisa qualitativa a partir da análise das respostas a um questionário de dez pessoas escolhidas ao acaso no Conjunto Nacional de Brasília, centro comercial situado ao lado da Rodoviária de Brasília, local onde se Revista Eletrônica: Tempo - Técnica - Território, V.1, N.3 (2010), P. 50:72 ISSN: 2177-4366 
interceptam os principais eixos rodoviários da cidade e por onde passam ônibus provenientes de todas as RA's do DF e de diversas cidades do entorno. O local também abriga a principal estação de trem metropolitano de Brasília. O Conjunto Nacional concentra desde lojas populares até lojas de

elevados padrões, o que faz com que seu público seja diversificado, com pessoas de diferentes níveis socioeconômicos.

A finalidade da pesquisa qualitativa, como aponta Gaskell (2003, p. 68), "não é contar opiniões ou pessoas, mas ao contrário, explorar o espectro de opiniões, as diferentes representações sobre o assunto em questão". A aplicação do questionário permitiu sondar a variedade de opiniões e representações sobre o meio ambiente e a natureza do cidadão comum do DF.

As perguntas do questionário foram elaboradas com o intuito de conhecer os processos pelos quais o cidadão do DF tem acesso à EA, verificar seu grau de envolvimento e sua consciência sobre as responsabilidades dos diversos atores sociais frente à problemática ambiental. Os respondentes foram enumerados de acordo com a ordem de realização das entrevistas.

Também foram realizadas entrevistas com dois especialistas em EA que atuam no DF. As entrevistam tiveram o propósito de verificar como os profissionais avaliam os programas de EA desenvolvidos no DF quanto à qualidade e abrangência.

O trabalho apresenta inicialmente a degradação da relação homem/natureza. Logo após são apresentados os problemas ambientais identificados no Distrito Federal. Em seguida, um breve histórico mostra como se desenvolveu a EA no DF para conscientizar os moradores quanto aos problemas verificados. Por fim, apresentamos os resultados da aplicação dos questionários e da realização das entrevistas.

\section{CONTEMPLAÇÃO DA CONSTRUÇÃO DO CONHECIMENTO GEOGRÁFICO COMO FORMA DE VERIFICAR A DEGRADAÇÃO DA RELAÇÃO HOMEM/NATUREZA}

Não é a toa que cresce e evolui a preocupação ambiental. A modernidade legou para a sociedade contemporânea maior conhecimento, desenvolvimento econômico e social, mas tudo desembocou em alterações no ambiente em todo mundo, causando prejuízo à boa qualidade de vida possibilitada pela própria modernidade.

A crise ambiental não surgiu de uma hora para outra. Percebida como uma crise mundial no século XX, ela resultou de um histórico processo de distanciamento entre homem e natureza. A 
crise se agravou na medida em que se desenvolveu o conhecimento e a técnica, ferramentas essenciais para que o homem pudesse dominar a natureza e torná-la útil aos seus propósitos. O problema é mundial, mas percebido especialmente em escala local. Sua complexidade e importância

exigem a articulação entre diferentes campos do saber e envolve questões de ordem física e humana. A Geografia como ciência de síntese e acostumada com a dicotomia natural e humano pode contribuir para o avanço do conhecimento em prol da resolução dos problemas ambientais. A contemplação da evolução do conhecimento geográfico permite visualizar o crescente afastamento entre ser humano e natureza desembocando na crise.

Desde a pré-história a humanidade sente a necessidade de conhecer o espaço em que habita para planejar ações e diminuir sua suscetibilidade ao meio natural, produzindo um ramo do conhecimento específico que viria a ser denominado de geografia. O termo, de acordo com Carvalho (1996), nasceu na Grécia clássica com a preocupação dos filósofos em descreverem o espaço. A Geografia sempre se empregou de descrever paisagens e territórios, relatar a vida cotidiana e as viagens. A prática atravessou o tempo e a partir das revoluções culturais iniciadas no período do Renascimento começou a firmar-se como ciência. Desde então existe uma recorrente preocupação em se definir objeto e método específicos para esta ciência, provocando constantemente rupturas em uma linha de pensamento e o advento de outra, com a reiterada consideração da relação entre as sociedades humanas e a natureza.

A Geografia ou a grafia da Terra, além de descrever a paisagem, se confundia com a Cartografia. Os gregos foram pioneiros na utilização de coordenadas geográficas, não demoraram a concluir que a Terra possui forma arredondada, calcularam com relativa precisão a circunferência da Terra, introduziram as teorias heliocêntricas, utilizavam instrumentos de navegação e, de acordo com Andrade (1987), estudaram a agricultura, as técnicas de uso do solo, a relação cidade/campo, a relação entre as classes sociais, a relação entre o povo e o poder, os sistemas de montanhas, os rios e seus variados regimes, a distribuição das chuvas, as estações do ano, dentre muitas outras conquistas.

No período das grandes navegações, o conhecimento obtido através da Geografia foi utilizado nas conquistas de novos territórios, forneceu informações aos navegantes, calculou distâncias de viagens, descreveu terras recém-descobertas, atendeu as necessidades dos povos para o comércio. Nesse momento histórico a exteriorização da natureza intensificou-se incentivada pela ampliação do comércio: "Desde o século XVI, a natureza é comercializada como uma mercadoria das mais 
lucrativas [...] A cultura do consumo fabricou valores comerciais compatíveis com o desenvolvimento e a expansão de mercados internacionais” (BARCELLOS, 2008, p. 109).

As grandes navegações foram precedidas pela inquietação cultural dos povos europeus que permitiram a criação de escolas navais, universidades e outras instituições que precipitaram o

renascimento cultural. O Renascimento representou a ruptura com o conhecimento antigo, formulando novas bases para o conhecimento. Desde então estas bases estão em constante aperfeiçoamento, porém, em constante inquietação.

O movimento racionalista retomou as intenções da ciência grega e fez com que a construção do conhecimento deixasse de ser exclusividade de determinados homens para se tornar algo possível a qualquer ser pensante. Para Gomes (1996) a natureza oculta e insondável foi rompida pelo sistema cartesiano, que transformou a natureza em um sistema de leis matemáticas estabelecidas por um Deus racional. O sistema mecanicista de Descartes foi importante na Geografia por que permitiu a concepção geométrica da natureza. A noção abstrata do espaço tornou possível a teorização abstrata e os modelos espaciais da Geografia.

Esta inquietação aprofundou-se e tornou-se dramática com o Iluminismo, movimento que lançou as bases da modernidade desenvolvendo a ciência a partir dos métodos da observação e da experiência. O Positivismo, mais célebre herdeiro do período iluminista, substituiu o conhecimento metafísico por um saber totalmente objetivo, geral, progressivo e afirmativo a partir de métodos que valorizaram o empirismo, a verificação de hipóteses e formulação de leis. O Iluminismo permitiu que o conhecimento avançasse de uma forma jamais vista. $\mathrm{O}$ avanço do conhecimento, de acordo com Harvey (1997), acabou por afastar cada vez mais homem e natureza. Ainda segundo Harvey (apud BARCELLOS, 2008), os ideais iluministas de emancipação e auto-realização, que se concretiza a partir da ruptura entre sujeito e natureza, sustenta a representação moderna da natureza como algo passível de uso e mercantilização.

A influência positivista transformou a Geografia em ciência moderna e as inquietações da modernidade se espelharam na sistematização da Geografia. A Geografia experimenta uma recorrente crise epistemológica em busca da definição de objeto e métodos próprios.

No período pós-moderno que experimentamos "se tornam relevantes para a ciência temas tradicionalmente relacionados com a arte, tais como a subjetividade, a singularidade e a capacidade geradora" (SCHNITMAN, 1996, p.15). O momento em que vivemos é de questionamento das leis gerais da ciência, propondo-se que elas se aplicam somente a áreas limitadas e que teorias 
alternativas coexistem sem que necessariamente se invalidem. De acordo com Schnitman, o mundo tornou-se complexo e se faz necessária uma reordenação intelectual que permita pensar a complexidade.

A diversidade, tão cara à pós-modernidade, é elemento chave no pensamento geográfico contemporâneo, conquistada pela constante preocupação em definir o objeto e os métodos próprios da Geografia, que provocou sucessivas rupturas em uma linha de pensamento e o advento de outra. As transformações ocorridas na Geografia ao longo da história foram motivadas, sobretudo, pelas transformações no contexto histórico e social, nas práticas sociais e na cultura, com implicações na ciência em geral. A ruptura dos paradigmas faz com que a Geografia se adapte às demandas da sociedade e fornece instrumentos para as mudanças e intervenções na realidade. Segundo Focault (1987) é nessas rupturas que o conhecimento se desenvolve. A Geografia deixou de ser uma simples descrição da paisagem, tornou-se ciência, experimentou diferentes objetos e métodos e chega à contemporaneidade utilizando-se de técnicas sofisticadas. A Geografia está preparada para a pósmodernidade: "as discussões sobre a pós-modernidade incidem freqüentemente sobre temas caros à tradição geográfica: o espaço, o urbano, o planejamento, o regionalismo, a escala local, a natureza, etc.” (Gomes, 1996, p.14).

Conforme menciona Paulo César da Costa Gomes (1996) a crescente desconfiança no projeto moderno e a decorrente crise na ciência positivista fizeram da Geografia uma ciência social, tendo o espaço geográfico como objeto. O modelo sócio-espacial enriqueceu a discussão ambiental na Geografia. Inicialmente a preocupação era apenas com a influência do espaço e da paisagem no comportamento humano. Posteriormente adicionou-se às preocupações a influência do ser humano no espaço e na paisagem. Esta abordagem surgiu em contraposição ao aumento da capacidade humana de alterar o ambiente, aliada a uma cultura consumista, que enxerga a natureza unicamente como fornecedora de matéria-prima.

\section{PROBLEMAS AMBIENTAIS DO DF}

Conforme relata Romero (2003), a partir da década de 1980 intensificaram-se os danos e o comprometimento ambiental do Distrito Federal, quadro acentuado na década de 1990, apresentando nos dias de hoje redução visível da qualidade de vida nas áreas mais susceptíveis.

Os principais problemas ambientais identificados no território do DF são: a contaminação da água pela utilização de fossas e lançamento de esgoto em locais inadequados; diminuição do nível 
dos lençóis e do fluxo dos cursos d'água devido à utilização de poços, sistemas de irrigação de grande porte, aterro de nascentes e destruição da vegetação nativa; incêndios florestais; perda da biodiversidade; parcelamento irregular de terras, inclusive em áreas de preservação ambiental.

Tais problemas apresentam conseqüências socioeconômicas como a ocorrência de doenças infectocontagiosas, a redução da disponibilidade de água potável, a perda de áreas destinadas ao lazer, a degradação da beleza cênica da paisagem, o prejuízo da qualidade do ar, a diminuição da disponibilidade de matéria-prima, o aumento dos conflitos para uso e ocupação do solo.

Os problemas ambientais do DF são grandes e estão interconectados. O consumo de água está ameaçado pela redução do nível fluxos de água e dos lençóis devido à utilização de grandes sistemas de irrigação, aterro de nascentes e poços de forma indiscriminada. Os poços se fazem necessários especialmente em parcelamentos irregulares de terra, que ameaçam também a preservação de atributos ambientais importantes e a existência de locais adequados para o necessário contato com a natureza. Nesses locais, a destruição da vegetação nativa ameaça a biodiversidade e contribui com a poluição por não possuírem destinação adequada para os resíduos sólidos. Os loteamentos inadequados inviabilizam a implementação de esgotamento sanitário, coleta de lixo e canalização da drenagem, o que contamina e assoreia as fontes de água e facilita a proliferação de vetores de doenças. A queima de lixo muitas vezes sai do controle e resulta em incêndios florestais, causados também pela deposição inadequada de pontas de cigarro e materiais que produzem calor em contato com a luz solar, especialmente às margens das rodovias.

Em cada um dos danos ao meio ambiente podemos enxergar a participação ou a omissão do cidadão. Ele é partícipe quando atua diretamente na promoção do dano. E ele é omisso quando se ausenta das "decisões sobre os destinos do território que ajudou a construir" (STEINBERGER, 2003, p. 293). Logicamente, ao homem comum não pode ser imputada toda responsabilidade pelos problemas ambientais. Em muitos dos problemas, as empresas ou até mesmo o governo possuem imputabilidade maior. $\mathrm{O}$ foco da presente pesquisa, porém, é o cidadão, que carrega consigo valores e comportamentos que são incorporados às empresas, ao governo, à sociedade como um todo. A resolução dos problemas ambientais necessita, portanto, de um processo que converta sua participação nos problemas em uma participação na resolução dos problemas.

A EA, então, apresenta-se como o processo adequado para despertar a cidadania e orientar a prática social para a resolução dos problemas ambientais, fazendo com que o cidadão contribua no seu cotidiano com a preservação da qualidade ambiental e participe das decisões políticas do lugar onde vive. Na próxima seção apresentamos aspectos da EA desenvolvida no território do DF. 


\section{EDUCAÇÃO AMBIENTAL NO DF}

A Política Nacional de Educação Ambiental - Lei número 9.795 de 27 de abril de 1999 entende por educação ambiental "os processos por meio dos quais o indivíduo e a coletividade constroem valores sociais, conhecimentos, habilidades, atitudes e competências voltadas para a conservação do meio ambiente". O Distrito Federal passou investir nesse processo quando começou a sentir os efeitos da degradação ambiental.

O primeiro trabalho significativo de EA desenvolvido no DF aconteceu em 1976, através de um convênio entre a Universidade de Brasília, a então Secretaria Especial de Meio Ambiente (SEMA) - órgão do poder executivo federal ${ }^{1}$ - e a então Fundação Educacional do Distrito Federal (FEDF) atual Secretaria de Estado de Educação (SE). O convênio viabilizou um curso de extensão para professores da FEDF com o objetivo de introduzir a temática ambiental no currículo das escolas. O trabalho foi inserido em um programa de EA desenvolvido pela UNESCO na Região Administrativa (RA) de Ceilândia, realizado em parceria com a FEDF. A Ceilândia é a RA mais populosa do DF e na época sofria com voçorocas provocadas pela impermeabilização do solo e a disposição inadequada da drenagem, com a poluição dos cursos hídricos, com a destruição do Cerrado, dentre outros problemas ambientais e sociais. As iniciativas tiveram fim poucos anos mais tarde, em 1981, mas introduziram a preocupação com o meio ambiente na gestão pública e no cidadão do DF.

Em 1985 foi criada a Coordenação de Assuntos do Meio Ambiente (COAMA) vinculada ao Gabinete Civil do Governador, órgão que introduziu a EA oficialmente na estrutura administrativa do Governo do Distrito Federal (GDF). A partir de então, a EA passou a fazer parte de diferentes órgãos ambientais e secretarias de estado de sucessivos governos até a criação do Instituto do Meio Ambiente e dos Recursos Hídricos do Distrito Federal - doravante chamado de Instituto Brasília Ambiental (IBRAM) - no ano de 2007.

A EA no DF talvez tenha vivido seu melhor momento entre 1991 e 1994 quando chegou a consumir $40 \%$ do orçamento anual da Secretaria de Meio Ambiente, Ciência e Tecnologia (SEMATEC), preocupada em frear a destruição do bioma Cerrado. Foram desenvolvidas campanhas como "Cerrado Sempre Vivo", "Papel Novamente Papel” e "Cerradim e Seus Amigos". Nessas campanhas foram desenvolvidas oficinas de arte e reciclagem e atividades culturais, teatrais e musicais com grande abrangência. "Cerradim e Seus Amigos", por exemplo, chegou a todas as

\footnotetext{
${ }^{1}$ O poder executivo federal, até entrar em vigor a Constituição Federal de 1988, era responsável pela administração do DF.
} 
escolas públicas do DF, atingiu cerca de 500 mil alunos, distribuiu revistas para as crianças e manuais para os professores (SEMATEC, 1994, p.25).

Os Núcleos de Educação Ambiental (NEAs), hoje um pouco esquecidos, também se destacaram no papel de despertar a consciência ambiental no cidadão do DF. Mantidos pelo IBAMA e/ou pelo GDF, os NEAs se fizeram presente em locais como o Parque Nacional de Brasília, o Museu Vivo da História Candanga, o palácio do Jaburu, o Parque Três Meninas em Samambaia, a Estação Ecológica de Águas Emendadas.

Importantes iniciativas de EA do GDF resistiram às alterações de governo. Dentre elas podemos destacar aquelas que ocorrem no Jardim Botânico e no Jardim Zoológico de Brasília. Autarquias do governo como a CAESB, a CEB, a EMATER ao longo dos anos também desenvolveram projetos relacionados com suas áreas de atuação.

A Secretaria de Educação conseguiu condensar as diferentes iniciativas de EA desenvolvidas pelo governo do DF, permitindo sua interação com os alunos. A Secretaria de Educação também mantém a Escola da Natureza que, desde 1996, desenvolve atividades com alunos da rede pública do Plano Piloto e oferece cursos para professores e representantes de instituições de defesa do meio ambiente. A Escola da Natureza está localizada no Parque da Cidade e planeja estender sua atuação para outras RA's do DF.

Boa parte da EA oferecida no DF tem as crianças como alvo principal. De acordo com a SEMATEC (1994, p.146) é muito mais fácil convencer a criança do que "demover conceitos antigos e implantar novos" nos adultos. A eficácia desta estratégia talvez seja desconhecida, mas é fato que as boa parte das crianças que participaram das atividades de EA desde as primeiras iniciativas na década de 1970 hoje são adultos que, podem ou não, estar colocando em prática os conceitos que aprenderam. Cabe o questionamento se o cidadão que recebeu educação ambiental contribuiu efetivamente para a solução dos seus problemas ambientais do DF, reflexão que será aprofundada na próxima seção.

\section{A OPINIÃO DO CIDADÃO DO DF SOBRE O MEIO AMBIENTE 4.1 QUESTIONÁRIO APLICADO AOS CIDADÃOS}

O questionário aplicado a freqüentadores do Conjunto Nacional de Brasília, tinha sete questões: 1) Quais os meios pelos quais você se informa sobre o meio ambiente e a natureza? 2) Existem informações suficientes sobre o meio ambiente? 3) O que fazer para melhorar a quantidade de informações? 4) Quem é responsável por levar a EA? 5) Você conhece entidades que promovem a EA? 6) Como tomou conhecimento dela? 7) Você participa ou já participou de alguma atividade de EA? Quais?

Revista Eletrônica: Tempo - Técnica - Território, V.1, N.3 (2010), P. 50:72 ISSN: 2177-4366 
A Tabela 1 sintetiza o perfil dos respondentes do questionário, quanto ao local de moradia, estado de origem, tempo no DF (ou no entorno), sexo e idade.

TABELA 1 - PERFIL DOS RESPONDENTES DO QUESTIONÁRIO

\begin{tabular}{|l|l|l|l|l|l|}
\hline Respondente & Local de Moradia & UF de Origem & Tempo no DF & Sexo & Idade \\
\hline $\mathbf{1}$ & Lago Norte & DF & 15 anos & F & 15 \\
$\mathbf{3}$ & São Sebastião & DF & 17 anos & M & 17 \\
$\mathbf{4}$ & Candangolândia & DF & 20 anos & F & 20 \\
$\mathbf{5}$ & Lago Sul & RS & 15 anos & F & 35 \\
$\mathbf{6}$ & Plano Piloto & AM & 8 meses & M & 19 \\
$\mathbf{7}$ & Luziânia & DF & 38 anos & F & 38 \\
$\mathbf{8}$ & Plano Piloto & DF & 24 anos & M & 24 \\
$\mathbf{9}$ & Paranoá & MA Emas & 5 anos & F & 25 \\
$\mathbf{1 0}$ & Plano Piloto & DF & 22 anos & F & 22 \\
\hline
\end{tabular}

Fonte: dos autores.

A Tabela 2 apresenta a escolaridade dos respondentes, bem como o tipo de escola em que estudaram e suas ocupações atuais.

TABELA 1 - ESCOLARIDADE E OCUPAÇÃO DOS RESPONDENTES

\begin{tabular}{|l|l|l|l|}
\hline Respondente & $\begin{array}{l}\text { Nível de } \\
\text { escolaridade }\end{array}$ & Tipo de Escola & Ocupação \\
\hline
\end{tabular}




\begin{tabular}{l|l|l|l}
\hline $\mathbf{1}$ & Ensino Médio & Particular & Estudante \\
$\mathbf{2}$ & Ensino Médio & Pública & Funcionário de Pequeno Comércio* \\
$\mathbf{3}$ & Ensino Médio & Pública & Funcionário de Pequeno Comércio** \\
$\mathbf{4}$ & Superior & Pública e Particular & Administrador \\
$\mathbf{5}$ & Ensino Fundamental & Pública & Estudante \\
$\mathbf{6}$ & Ensino Médio & Pública & Autônomo \\
$\mathbf{7}$ & Superior & Pública e Particular & Estudante \\
$\mathbf{8}$ & Ensino Médio & Pública e Particular & Desempregado \\
$\mathbf{9}$ & Ensino Médio & Pública & Funcionário de Pequeno Comércio*** \\
$\mathbf{1 0}$ & Superior & Pública e Particular & Autônomo \\
\hline Legenda: & *Papelaria & ***anificadora & *anchonete \\
\hline
\end{tabular}

Fonte: dos autores.

Os respondentes moram no DF ou em cidade do entorno ${ }^{2}$. A maior parte nasceu no DF e os demais são provenientes de diferentes regiões do país. Sete dos dez são do sexo feminino. Seis dos dez respondentes cursam ou cursaram o Ensino Médio, três cursam ou cursaram o nível superior e apenas um possui nível fundamental de escolaridade. Metade dos respondentes estudou somente em escola pública, quatro estudaram tanto em escolas públicas como também em privadas e apenas um estudou somente em escolas privadas. Todos os respondentes que trabalham são da iniciativa privada.

A caracterização dos respondentes objetivou a verificação da ocorrência de maior ou menor participação do cidadão na resolução de problemas ambientais em função do local de moradia e tempo de moradia no DF, idade, sexo, grau de escolaridade, tipo de escola e ocupação. Aparentemente a consciência ambiental do cidadão do DF independe dessas variáveis. Mas é preciso considerar também que a abordagem qualitativa da pesquisa fez com que a amostra fosse muito pequena para se observar padrões de respostas em função de tais variáveis. As respostas às sete perguntas do questionário estão relacionadas na Tabela 3.

$\mathrm{Na}$ tabela, o enunciado das questões e as respostas dadas foram resumidos para sua inserção na tabela, mas foi preservado o conteúdo principal.

TABELA 3 - RESPOSTAS DADAS AO QUESTIONÁRIO

\begin{tabular}{|l|l|}
\hline \multicolumn{2}{|l|}{ SOBRE AS INFORMAÇÕES RECEBIDAS SOBRE O MEIO AMBIENTE E A NATUREZA } \\
\hline$a \quad$ QUESTÕES \\
$\begin{array}{l}{ }^{2} \text { O alto preço dos imóveis em Brasília faz com que muitas pessoas que nasceram, trabalham e que vivem boa parte do } \\
\text { tempo no DF estabeleçam moradia em cidades do entorno, como é o caso do respondente que mora em Luziânia. } \\
\text { Revista Eletrônica: Tempo - Técnica - Território, V.1, N.3 (2010), P. 50:72 ISSN: } 2177-4366\end{array}$ \\
\end{tabular}




\begin{tabular}{|c|c|c|c|}
\hline & $\begin{array}{l}\text { 1) Meios pelos quais se } \\
\text { informa sobre o meio } \\
\text { ambiente e a natureza: }\end{array}$ & $\begin{array}{l}\text { 2) Existem informações } \\
\text { suficientes sobre o meio } \\
\text { ambiente? }\end{array}$ & $\begin{array}{l}\text { 3) O que fazer para } \\
\text { melhorar a quantidade de } \\
\text { informações? }\end{array}$ \\
\hline 1 & Escola & Não & Propagandas nas ruas, na TV \\
\hline 2 & TV e internet & Não & Conscientização nas escolas \\
\hline 3 & TV & Não & $\begin{array}{l}\text { Maior rigidez das leis e do } \\
\text { Estado }\end{array}$ \\
\hline 4 & $\begin{array}{l}\text { TV, livros, revistas e } \\
\text { internet }\end{array}$ & Sim & $\begin{array}{l}\text { Projetos nas escolas para } \\
\text { crianças }\end{array}$ \\
\hline 5 & TV e internet & Não & Discussões e debates \\
\hline 6 & TV & Não & $\begin{array}{l}\text { Campanhas do Estado em } \\
\text { jornais, rádio e revistas }\end{array}$ \\
\hline 7 & TV e familiares & Não & $\begin{array}{l}\text { Documentários na } \mathrm{TV} \text { e } \\
\text { panfletos }\end{array}$ \\
\hline 8 & TV e rádio & Não & Não sei \\
\hline 9 & Escola e TV & Não & Não sei \\
\hline 10 & TV & Não & $\begin{array}{l}\text { Campanhas na TV e } \\
\text { congresso como a Rio } 92\end{array}$ \\
\hline \multicolumn{4}{|c|}{ SOBRE AS RESPONSABILIDADES PELA EDUCAÇÃO AMBIENTAL } \\
\hline \multirow[b]{2}{*}{ 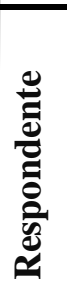 } & \multicolumn{3}{|l|}{ QUESTÕES } \\
\hline & $\begin{array}{l}\text { 4) Quem é responsável } \\
\text { por levar a EA? }\end{array}$ & $\begin{array}{l}\text { 5) Conhece entidades que } \\
\text { promovem a EA? }\end{array}$ & $\begin{array}{l}\text { 6) Como tomou } \\
\text { conhecimento? }\end{array}$ \\
\hline 1 & Todo mundo & Não & \\
\hline 2 & Cada um deve fazer sua parte & Não & \\
\hline 3 & As escolas e o governo & Não & \\
\hline 4 & $\begin{array}{l}\text { Governo, MEC e Secretaria } \\
\text { de Educação }\end{array}$ & Não & \\
\hline 5 & Governo e estudantes & Não & \\
\hline 6 & Governo e população & Não & \\
\hline 7 & Governo & Não & \\
\hline 8 & Todos devem orientar quando & Não & \\
\hline
\end{tabular}




\begin{tabular}{l|l|l|l}
\hline & vê o outro fazendo errado & & \\
\hline $\mathbf{9}$ & Não sei & Não & \\
\hline $\mathbf{1 0}$ & $\begin{array}{l}\text { Todos, mas o governo tem } \\
\text { maior condição }\end{array}$ & Sim, o IDA & Reunião de condomínio \\
\hline
\end{tabular}

SOBRE A PARTICIPAÇÃO EM ATIVIDADE DE EDUCAÇÃO AMBIENTAL

\begin{tabular}{|c|c|c|}
\hline \multirow[b]{2}{*}{ 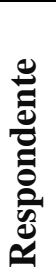 } & \multicolumn{2}{|l|}{ QUESTÕES } \\
\hline & $\begin{array}{l}\text { 7) Participa ou já participou de alguma } \\
\text { atividade de EA? }\end{array}$ & Qual? \\
\hline 1 & Sim & Plantio na escola \\
\hline 2 & Sim & Plantio na escola \\
\hline 3 & Sim & Reciclagem na escola \\
\hline 4 & Sim & $\begin{array}{l}\text { Atividades na escola e passeios com } \\
\text { crianças }\end{array}$ \\
\hline 5 & Sim & $\begin{array}{l}\text { Divulgação de informações na área da } \\
\text { saúde }\end{array}$ \\
\hline 6 & Não & \\
\hline 7 & Não & \\
\hline 8 & Não & \\
\hline 9 & Não & \\
\hline 10 & Não & \\
\hline
\end{tabular}

Fonte: dos autores.

Programas de televisão certamente são as principais fontes de informação do cidadão do DF a respeito das questões ambientais. A televisão é citada em nove das dez respostas à pergunta sobre os meios pelos quais o respondente se informa sobre o meio ambiente e a natureza. Em três das respostas a televisão aparece como a única fonte. As demais fontes citadas foram: a escola, a internet, livros, revistas, rádio e até outras pessoas. Dessas, a internet e a escola parecem ser as mais importantes.

A quantidade e a qualidade das informações veiculadas na TV, no entanto, parece não ser satisfatória, porque na questão seguinte, sobre a suficiência das informações, nove dos dez respondentes mostram-se insatisfeitos. A insatisfação parece estender-se também às informações provenientes de outras fontes, pois se repete nos respondentes que citaram fontes diversas. Um único respondente mostrou satisfação com as informações disponíveis sobre o meio ambiente e a natureza. Este é o respondente que apresenta uma diversidade maior de meios pelos quais se Revista Eletrônica: Tempo - Técnica - Território, V.1, N.3 (2010), P. 50:72 ISSN: 2177-4366 
informa sobre a questão ambiental. Sua satisfação parece estar atrelada a um interesse pessoal na questão e não em uma condição social.

A deficiência percebida pelo cidadão no conhecimento oferecido pela televisão e outras mídias é confirmada quando se analisa as respostas sobre o que fazer para melhorar a disponibilidade de informações. Quatro respondentes aconselham o aumento da veiculação de informações nos meios de comunicação em massa. Também figuram entre as propostas do cidadão a conscientização nas escolas, a distribuição de cartilhas e panfletos, maior rigidez do Estado para o cumprimento das leis ambientais, a realização de congressos, discussões e debates. Estas últimas talvez sejam resultado da repercussão que as convenções sobre o meio ambiente têm nos meios de comunicação. Um dos respondentes até cita a convenção que ficou conhecida como Rio Eco-92, uma das que mais tiveram repercussão nos meios de comunicação. Dois respondentes manifestaram não saber o que é necessário para a melhoria da disponibilidade de informações disponíveis sobre o meio ambiente e a natureza, apesar de constatarem sua insuficiência. O conflito no discurso para tratar da questão ambiental talvez represente insegurança a respeito do tema, cujos conhecimentos seriam superficiais.

O cidadão tem a consciência de que a EA é um processo de responsabilidade coletiva, porém, reconhece que o governo tem um papel preponderante, especialmente através das instituições de ensino. A preponderância atribuída à responsabilidade do governo parece estar atrelada à percepção de que o governo dispõe de maiores recursos.

O cidadão demonstra total desconhecimento das iniciativas de EA desenvolvidas no DF. Isto demonstra que as iniciativas apresentadas na segunda seção deste trabalho estiveram restritas a uma parcela da população. Um único respondente relatou conhecer uma instituição promotora de EA e ainda assim sem um contato direto. Tomou conhecimento dela através de uma reunião de condomínio, referindo-se à instituição unicamente através de uma sigla, cujo significado não conhecia. Ao que tudo indica a instituição é uma iniciativa não-governamental.

Metade dos respondentes disse nunca ter participado de alguma atividade de EA ou proteção do meio ambiente. A outra metade relata participação em pequenos projetos de plantio de árvores e oficinas de reciclagem, principalmente na escola. Um dos respondentes, além de ter participado de atividades escolares, relata que leva as crianças para passeios em áreas de preservação. Outro respondente relata que trabalhou para um órgão de saúde pública, onde orientava pessoas com informações a respeito de manter o ambiente saudável, evitar vetores de doenças, etc. Uma participação vinculada a uma atividade remunerada. 
$\mathrm{Na}$ próxima seção veremos que existem pontos comuns nas opiniões e representações do cidadão e nas opiniões e representações de especialistas em EA no DF.

\subsection{ENTREVISTAS COM ESPECIALISTAS}

Para maior aprofundamento na reflexão proposta por esta pesquisa foram realizadas duas entrevistas com propósito. Os entrevistados são especialistas em EA com ampla atuação no DF. O primeiro entrevistado possui especialização lato sensu em Educação Ambiental e trabalha há vários anos em uma instituição pública do $\mathrm{DF}$ promotora de EA. O segundo entrevistado é $\mathrm{PhD}$ em Ecologia, trabalha há muito tempo com EA sendo, inclusive, autor de vários livros sobre o tema.

Através das entrevistas procurou-se também confrontar as impressões retiradas da análise das respostas dos cidadãos com a opinião dos especialistas e esclarecer interrogações que surgiram após a aplicação dos questionários. Para tanto foram realizadas as seguintes perguntas: Quais foram os programas de EA já desenvolvidos no DF? Quais sãos os programas de EA desenvolvidos atualmente? Quais são os locais em que ocorrem essas atividades? Quais as dificuldades enfrentadas pelo processo de EA no DF? É adequado o quantitativo de pessoas atingidas pela EA no DF? Existem localidades em que as atividades de EA são mais intensas; por quê? A qualidade da EA varia de um programa para outro no DF? A mídia é um elemento importante no processo de EA?

As respostas dos especialistas a respeito dos programas de EA desenvolvidos no DF ao longo dos anos ajudaram a elaborar a segunda seção deste trabalho. Os especialistas compartilham opiniões semelhantes a respeito das dificuldades enfrentadas por esses programas, conforme podemos observar na Tabela 4.

TABELA 4 - DIFICULDADES ENFRENTADAS PELA EA NO DF

\begin{tabular}{|c|c|c|}
\hline Dific & stado & entrevistado \\
\hline $\begin{array}{l}\text { Oposição } \\
\text { governantes }\end{array}$ & $\begin{array}{l}\text { Os programas de governo } \\
\text { geralmente contemplam o ser } \\
\text { humano, esquecendo as demais } \\
\text { espécies. Não consideram que a } \\
\text { existência humana só possível } \\
\text { devido a existência de outras } \\
\text { espécies. }\end{array}$ & $\begin{array}{l}\text { No Brasil a EA nasceu no meio } \\
\text { dos movimentos sociais e era } \\
\text { considerada uma atividade } \\
\text { subversiva pelo regime militar. } \\
\text { No DF, governos chegaram a } \\
\text { desaprovar a EA e a criar } \\
\text { dificuldades para que os servidores } \\
\text { a promovessem. }\end{array}$ \\
\hline Ansla & s empecilhos à EA são resultados & rno a EA era \\
\hline
\end{tabular}




\begin{tabular}{|c|c|c|}
\hline $\begin{array}{l}\text { desenvolvimento } \\
\text { econômico }\end{array}$ & $\begin{array}{l}\text { da cultura brasileira que considera } \\
\text { que a proteção do meio ambiente } \\
\text { prejudica o desenvolvimento } \\
\text { econômico. Quando aprende algo, } \\
\text { a sociedade sempre se pergunta: "o } \\
\text { que vou ganhar com isso?" } \\
\text { Considerando apenas ganhos } \\
\text { econômicos, desprezando os } \\
\text { ambientais e sociais. Em Brasília, } \\
\text { então, existe uma "megalomania" } \\
\text { pelo desenvolvimento econômico. } \\
\text { Para isso realizam grandes obras e } \\
\text { não consideram } \\
\text { desenvolvimento deve ser também } \\
\text { social e ambiental. Chegaremos a } \\
\text { um ponto insuportável. }\end{array}$ & $\begin{array}{l}\text { motivada pela idéia de que ela } \\
\text { prejudicava o desenvolvimento } \\
\text { econômico. }\end{array}$ \\
\hline $\begin{array}{l}\text { Especulação } \\
\text { imobiliária }\end{array}$ & & $\begin{array}{l}\text { O setor imobiliário no } \mathrm{DF} \\
\text { representa uma força contrária à } \\
\text { questão ambiental: promove } \\
\text { invasão de áreas de preservação, } \\
\text { loteia sobre locais indevidos, sobre } \\
\text { nascentes e assim por diante. }\end{array}$ \\
\hline $\begin{array}{l}\text { O governo possui } \\
\text { outras prioridades }\end{array}$ & $\begin{array}{l}\text { O governo considera a questão } \\
\text { ambiental importante, mas possui } \\
\text { outras prioridades. Ele aprova } \\
\text { obras do PAC, mas não } \\
\text { implementa melhorias nos parques, } \\
\text { por exemplo, porque eles não são } \\
\text { prioridade. }\end{array}$ & \\
\hline $\begin{array}{l}\text { Obstáculos para } \\
\text { converter }\end{array}$ & $\begin{array}{l}\text { Muita coisa é colocada no papel, } \\
\text { mas não é colocada em prática, um }\end{array}$ & $\begin{array}{l}\text { Faltam iniciativa e vontade } \\
\text { política. O DF sabe o que precisa }\end{array}$ \\
\hline
\end{tabular}




\begin{tabular}{|c|c|c|}
\hline $\begin{array}{l}\text { intenção } \\
\text { prática }\end{array}$ & exemplo disso é a Agenda 21. & $\begin{array}{l}\text { ser feito, no entanto, não oferece } \\
\text { transporte coletivo de qualidade, } \\
\text { não cuida das áreas de preservação, } \\
\text { etc. }\end{array}$ \\
\hline $\begin{array}{l}\text { Ausência } \\
\text { recursos }\end{array}$ & $\begin{array}{l}\text { A sociedade não tem } \\
\text { comportamento compatível com a } \\
\text { proteção do meio ambiente por que } \\
\text { não recebe uma EA continuada e } \\
\text { de qualidade, e isso não é possível } \\
\text { por que não existe verba específica } \\
\text { para a EA. A Escola da Natureza, } \\
\text { por exemplo, deixou de atender } \\
\text { outras RA's do DF e passou a } \\
\text { atender somente o Plano Piloto. } \\
\text { Era inviável a locomoção para } \\
\text { outros locais por que ela não } \\
\text { possui sequer um veículo próprio. } \\
\text { Os professores se deslocavam para } \\
\text { dar cursos e palestras utilizando } \\
\text { veículo e combustível próprios, e } \\
\text { até desenvolviam projetos com os } \\
\text { próprios salários. }\end{array}$ & $\begin{array}{l}\text { Muitas iniciativas de EA no DF } \\
\text { aconteceram de forma isolada não } \\
\text { sistematizada e sem apoio. Alguns } \\
\text { professores desenvolvem projetos } \\
\text { nas escolas sem nenhum recurso. A } \\
\text { Escola da Natureza é um exemplo } \\
\text { de uma instituição que trabalha } \\
\text { bastante, mas sem recursos } \\
\text { adequados. }\end{array}$ \\
\hline $\begin{array}{l}\text { Descontinuidade } \\
\text { dos projetos }\end{array}$ & $\begin{array}{l}\text { Os projetos que existem no DF não } \\
\text { são sistematizados. Acontecem de } \\
\text { forma isolada e não são } \\
\text { continuados. Os projetos não } \\
\text { podem ser somente de uma pessoa } \\
\text { ou uma instituição. Nas escolas, se } \\
\text { mudam os professores acabam os } \\
\text { projetos. Quando mudam as } \\
\text { secretarias os projetos acabam. }\end{array}$ & $\begin{array}{l}\text { O DF não possui uma política } \\
\text { estadual de EA o que prejudica a } \\
\text { continuidade dos projetos. }\end{array}$ \\
\hline
\end{tabular}

Fonte: dos autores.

Com relação à abrangência da EA no DF, ambos especialistas disseram que o quantitativo de pessoas atingidas é insuficiente. O primeiro especialista relata que os trabalhos de EA ainda não 
conseguiram envolver os diferentes setores da sociedade, tais como, governo, escolas públicas e privadas, instituições civis e a iniciativa privada. A difusão das atividades de EA é prejudicada pela falta de recursos, como aconteceu com a Escola da Natureza, que concentrou suas atividades em um só local por não possuir recursos para manter outros projetos.

O segundo especialista é enfático em dizer que o DF possui uma população "analfabeta ambiental". Ele relata que uma parcela ínfima da população possui alguma informação e que as pessoas assistem a degradação ambiental sem mesmo ter a percepção de que há uma coisa errada. Não sabem o que é qualidade de vida, não sabem quanto ela pode melhorar com áreas de preservação por perto e não as defendem, não participam de protestos e passeatas para cobrar melhorias. Para o especialista a desinformação independe do local de moradia ou da classe social. Existe, desde o rico que mantém um padrão elevadíssimo de consumo, que muito demanda dos recursos naturais, que caça por diversão, etc. Como também existe o pobre que queima trinta hectares de mata para matar um preá (espécie de roedor). As pessoas depredam as áreas de preservação, como no Guará. Erguem edifícios em áreas de nascentes, como em Águas Claras. Seria arriscado dizer que em uma cidade existe maior número de pessoas com acesso à EA do que em outra. Seriam necessários estudos mais aprofundados para afirmar com certeza. Talvez nas cidades mais antigas a EA esteja mais difundida por que houve maior tempo para consolidação. Por isso, talvez a população do Lago Sul possa demonstrar maior consciência do que a do Itapoã, guardadas as diferenças na qualidade de ensino entre uma população e outra. Mas de forma geral a insuficiência da EA é generalizada.

Nem mesmo os meios de comunicação em massa têm conseguido atingir a população de forma satisfatória. Ambos entrevistados reclamam da falta de estrutura, do repasse de informações de forma aleatória, em horários em que a maioria das pessoas não tem acesso, enquanto o horário nobre é ocupado por programas fúteis.

O primeiro entrevistado acha que nem mesmo os que assistem aos programas do horário nobre concordam com tanta futilidade nesse horário. Recomenda inclusive a realização de uma enquete se as pessoas preferem o "Pânico na TV" ou programa educativo e mobilizador de EA no horário.

O segundo entrevistado considera que a mídia no Brasil desenvolve um trabalho primário se comparado ao nível atingido pelos Estados Unidos, pela Europa e pela Ásia onde há um trabalho sistematizado e contínuo. De acordo com ele, as iniciativas aqui são ínfimas e com uma visão demasiadamente primária. Existe tanto a abordagem romântica do meio ambiente, quando mostram a flora e a fauna, como também existe a abordagem catastrófica para intimidar as pessoas. Segundo 
o entrevistado, são abordagens ingênuas, por que não conduzem o cidadão a um comportamento compatível com a proteção do meio ambiente. Na mídia impressa, poucas jornalistas abordam o assunto e aqueles que abordam não têm reconhecimento.

Os questionários aplicados com cidadãos e as entrevistas com especialistas deixam clara a necessidade de se repensar a EA oferecida no DF.

\section{CONSIDERAÇÕES FINAIS}

A EA chegou ao DF em momento oportuno: quando os problemas ambientais começaram a ameaçar a qualidade de vida da população e quando havia grande clamor mundial pela proteção do meio ambiente, nos anos de 1970. O DF também esteve na vanguarda com relação à criação de órgãos ambientais.

Apesar do surgimento oportuno, a EA no DF pouco evoluiu desde o seu início e apesar do surgimento precoce dos órgãos ambientais, as alterações devido às mudanças de governo inviabilizaram a continuidade dos projetos ao longo do tempo. O resultado disso é uma população que, ao invés de participar da melhoria do ambiente em que vive, participa da sua destruição de forma direta ou de forma indireta através da sua omissão política.

As audiências públicas, os Comitês de Bacia Hidrográfica, as Comissões de Meio Ambiente, dentre outros, são instrumentos que possibilitam a participação popular na política ambiental, porém, a abstinência é muito grande. A omissão política do brasiliense provoca a sobreposição dos interesses econômicos aos interesses sociais, favorece a atuação dos especuladores imobiliários e até de políticos de corruptos, em detrimento do bem-estar da população. Os interesses econômicos, imobiliários e políticos, talvez sejam responsáveis também por outro problema crônico da EA no DF: a falta de recursos, quando conseguem que seus representantes cheguem ao poder.

Problemas externos não são os únicos da EA no DF. Existem também problemas internos como a percepção de que a crise ambiental pode ser enfrentada apenas com oficinas de reaproveitamento de materiais, reciclagem de papel, plantio de mudas e palestras sobre catástrofes a nível mundial, sem considerar que a solução do problema mundial perpassa pela solução a nível local.

A aplicação dos questionários e as entrevistas mostraram que os meios de comunicação são mais importantes para o processo de EA do que se pensava inicialmente. Este é um dos meios no qual a interferência do governo é menor, porém, não é nula. O governo pode utilizar-se deles na forma de propagandas ou mesmo buscando parcerias para levar uma EA mais apropriada do que aquela que tem sido veiculada e até mesmo em horários mais adequados. 
As pesquisas realizadas mostraram que o cidadão, de forma geral, desconhece as atividades de EA desenvolvidas pelo governo. Essas atividades só podem atingir a população de forma efetiva quando os investimentos e a sensibilização forem pelo menos próximo do que foram entre os anos de 1991 e 1994.

A Fundação Educacional e posteriormente a Secretaria de Educação apresentaram-se como as instituições que mais fizeram pela EA no DF. Sua capacidade de mobilização e abrangência deve ser considerada por outros órgãos e outros projetos que buscam parcerias. 


\section{REFERÊNCIAS BIBLIOGRÁFICAS}

ANDRADE, Manuel. Geografia, ciência da sociedade: uma introdução à análise do pensamento geográfico. São Paulo: Ática, 1987.

BARCELlOS, Gilsa. A Crise Ambiental e a Mercantilização da Natureza. In HISSA, Cássio (Org). Saberes Ambientais: Desafios para o conhecimento disciplinar. Belo Horizonte: Editora UFMG, 2008. (Humanitas).

BRASIL. Constituição Federal de 1988. Brasília: Senado Federal, 1997. (Edições Técnicas).

BRASIL. Lei número 9.795 de 27 de abril de 1999. Dispõe sobre a Educação Ambiental, Institui a Política Nacional de Educação Ambiental e dá outras providências. Disponível em: //www.planalto.gov.br/. Acesso em: 15 de novembro de 2009.

CARVALHO, Márcia. A Geografia desconhecida. Londrina: Eduel, 1996.

DIAS, G. Fundamentos de Educação Ambiental. Brasília: Editora Universa, 2004. 3.ed.

DISTRITO FEDERAL. Lei número 3.833, de 27 de março de 2006. Dispõe sobre a educação ambiental, institui a Política de Educação Ambiental do Distrito Federal, cria o Programa de Educação Ambiental do Distrito Federal, complementa a Lei Federal nº 9.795/ 99 no âmbito do Distrito Federal, e dá outras providências. Brasília: DODF, 04 de abril de 2006.

GASKELL, G. Entrevistas Individuais e Grupais. In BAUER, M. e GASKELL, G. (Org's) Pesquisa Qualitativa com Texto, Imagem e Som: Um manual prático. Petrópolis: Vozes, 2003. Tradução: Pedrinho A. Guareschi.

GOMES, Paulo. Geografia e modernidade. Rio de Janeiro: Bertrand do Brasil, 1996.

HARVEY, David. Justice, nature and the Geography of diference. Massachusetts: Blackwell Publishers, 1997.

MAURY, M. e MAIOR, G. Apresentação. In IBRAM. Revista Recaminho. Brasília: IBRAM, 2009. 1. ed. 
ROMERO, M. A sustentabilidade do meio ambiente urbano da capital. In PAVIANI, A. e GOUVÊA, L (Org’s). Brasília: Controvérsias ambientais. Brasília: Editora UnB, 2003 (Coleção Brasília).

SCHNITMAN, Dora. Introdução: ciência, cultura e subjetividade. In SCHNITMAN, Dora. Novos paradigmas, cultura e subjetividade. Porto Alegre: Artes Médicas, 1996, p. 9-24.

SEMATEC. Anais da II Conferência de Meio Ambiente do Distrito Federal. Brasília: Secretaria do Meio Ambiente, Ciência e Tecnologia, 1994.

STEINBERGER, M. Zoneamento Ecológico-Econômico: instrumento geoestratégico. In PAVIANI, A. e GOUVÊA, L (Org's). Brasília: Controvérsias ambientais. Brasília: Editora UnB, 2003 (Coleção Brasília). 